\title{
Article
}

\section{Two Unconventional Metallothioneins in the Apple Snail Pomacea bridgesii Have Lost Their Metal Specificity during Adaptation to Freshwater Habitats}

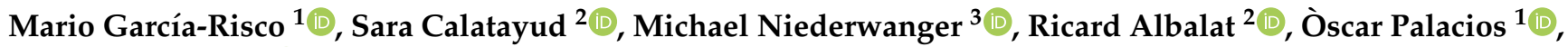 \\ Mercè Capdevila ${ }^{1}\left[\right.$ and Reinhard Dallinger ${ }^{3, *}$ \\ 1 Departament de Química, Facultat de Ciències, Universitat Autònoma de Barcelona, \\ E-08193 Cerdanyola del Vallès, Spain; Mario.GarciaRisco@uab.cat (M.G.-R.); oscar.palacios@uab.cat (Ò.P.); \\ merce.capdevila@uab.cat (M.C.) \\ 2 Departament de Genètica, Microbiologia i Estadística and Institut de Recerca de la Biodiversitat (IRBio), \\ Facultat de Biologia, Universitat de Barcelona, Av. Diagonal 643, E-08028 Barcelona, Spain; \\ sarak09@hotmail.com (S.C.); ralbalat@ub.edu (R.A.) \\ 3 Institute of Zoology, Center of Molecular Biosciences, University of Innsbruck, Technikerstraße 25, \\ A-6020 Innsbruck, Austria; michael.niederwanger@uibk.ac.at \\ * Correspondence: reinhard.dallinger@uibk.ac.at
}

check for updates

Citation: García-Risco, M.; Calatayud, S.; Niederwanger, M.; Albalat, R.; Palacios, Ò.; Capdevila, M.; Dallinger, R. Two Unconventional Metallothioneins in the Apple Snail Pomacea bridgesii Have Lost Their Metal Specificity during Adaptation to Freshwater Habitats. Int. J. Mol. Sci. 2021, 22, 95. https://dx.doi.org/10.3390/ ijms22010095

Received: 26 November 2020 Accepted: 18 December 2020 Published: 24 December 2020

Publisher's Note: MDPI stays neutral with regard to jurisdictional claims in published maps and institutional affiliations.

Copyright: (c) 2020 by the authors. Licensee MDPI, Basel, Switzerland. This article is an open access article distributed under the terms and conditions of the Creative Commons Attribution (CC BY) license (https: / / creativecommons.org/ licenses/by/4.0/).

\begin{abstract}
Metallothioneins (MTs) are a diverse group of proteins responsible for the control of metal homeostasis and detoxification. To investigate the impact that environmental conditions might have had on the metal-binding abilities of these proteins, we have characterized the MTs from the apple snail Pomacea bridgesii, a gastropod species belonging to the class of Caenogastropoda with an amphibious lifestyle facing diverse situations of metal bioavailability. P. bridgesii has two structurally divergent MTs, named PbrMT1 and PbrMT2, that are longer than other gastropod MTs due to the presence of extra sequence motifs and metal-binding domains. We have characterized the $\mathrm{Zn}$ (II), $\mathrm{Cd}(\mathrm{II})$, and $\mathrm{Cu}(\mathrm{I})$ binding abilities of these two MTs after their heterologous expression in E. coli. Our results have revealed that despite their structural differences, both MTs share an unspecific metal-binding character, and a great ability to cope with elevated amounts of different metal ions. Our analyses have also revealed slight divergences in their metal-binding features: PbrMT1 shows a more pronounced $\mathrm{Zn}(\mathrm{II})$-thionein character than PbrMT2, while the latter has a stronger $\mathrm{Cu}(\mathrm{I})$ thionein character. The characterization of these two unconventional PbrMTs supports the loss of the metal-binding specificity during the evolution of the MTs of the Ampullariid family, and further suggests an evolutionary link of this loss with the adaptation of these gastropod lineages to metal-poor freshwater habitats.
\end{abstract}

Keywords: metallothionein; metal-specificity; protein domains; Pomacea bridgesii; Mollusca; Gastropoda

\section{Introduction}

Metallothioneins (MTs) are usually small proteins known for their singularly high content of cysteine residues (Cys), which provide them the capacity for binding essential and non-essential heavy metal ions [1-3]. Since MT samples are natively found in association with metals their functions have been related with biological processes involving metal-binding [4]. Some organisms have achieved metal-specific functions of their MTs by harboring multiple forms, each one with a different metal preference [5,6]. Some gastropods, such as Cantareus aspersus (also known as Helix aspersa or Cornu aspersum) and Helix pomatia, for instance, exhibit different highly specific MTs devoted to selectively bind $\mathrm{Cd}$ (II) (CdMTs) or Cu(I) (CuMTs) [5,7]. Since the expression of CdMTs is upregulated by $\mathrm{Cd}^{2+}$ ions, these MTs have been associated with the physiological control of $\mathrm{Cd}$, specifically with Cd detoxification [8-10], whereas the expression of CuMTs appears to be activated for 
controlling $\mathrm{Cu}$ homeostasis, which in the case of gastropods is related to the synthesis of the oxygen transporter hemocyanin $[5,11]$.

Interestingly, comparisons of the number and distribution of the $\mathrm{Cys}$ motifs (i.e., $\mathrm{CxC}$, $\mathrm{CC}$, and CCC) between MTs have led to conclude that CdMTs and CuMTs of a given group of species derived from duplication events of a common MT ancestor [12], and that changes in the non-coordinating amino acids of the duplicates would have been responsible for the evolution of distinct metal binding preferences [12]. Their frequency and positioning within the sequence, along with their spatial arrangement in the three-dimensional structure determine the metal-selectivity of the protein [7,12-14]. In addition to the CdMT and CuMT isoforms, C. aspersus and H. pomatia express a third MT isoform with intermediate metallic preferences, yielding mixtures of heterometallic metal-complexes when recombinantly synthesized [5,14] or characterized from native MT preparations [15]. These unspecific MTs seem multipurpose proteins capable of maintaining either the physiological levels of metals in the cell [16], transferring them to other metalloproteins [17], or binding toxic heavy metals in order to avoid their deleterious effects [18]. Paradoxically, the amino acid sequences of the three types of gastropod MTs-CdMT, CuMT and unspecific MTare extremely similar despite their different functionalities. To overcome the difficulties of classifying these clearly different proteins, two criteria were proposed based on MTs metal-binding features on the one hand $[19,20]$ and their metal-specific functionality on the other [6,7]. The first criterion is based on metal selectivity of MTs through rendering unique, well-structured, homometallic metal-complexes when binding either divalent (Cd(II) or $\mathrm{Zn}$ (II) for $\mathrm{Cd} / \mathrm{Zn}$-thioneins) or monovalent metal ions (Cu(I) for Cu-thioneins) [20], and to render a mixture of heterometallic complexes for non-selective MTs somewhere in the middle of this gradual classification [19]. The second criterion is based on physiological evidence indicating a prevalent functionality of the respective MTs in performing metalspecific tasks in favor of the metal ion selectively bound, or in favor of a multi-task performance in case of non-selective MTs [5,7-9].

Intriguingly, some gastropod species possess a full set of MTs with different metal binding preferences (CdMTs, CuMTs and unspecific MTs), whereas others like Megathura crenulata [21] and Biomphalaria glabrata [22] only express unspecific MTs. The diversity of gastropods, as well as of their MTs, is actually so high that the study of gastropod MTs is becoming more and more a model case in the field of MT research $[13,23]$. The present study adds to this field novel evidence, being devoted to the characterization of two unconventional MTs found in P. bridgesii (PbrMT1 and PbrMT2) [13,23]. This species belongs to the group of freshwater apple snails (family Ampullariidae) of the gastropod class of Caenogastropoda, some of them known for their vast ecological impact as pests [24,25]. These snails are also unusual because they possess both a gill and a lung, situated in separated compartments of their mantle cavity. Owing to this particular adaptation, apple snails have assumed an amphibious lifestyle, by which they live predominantly in freshwater swamps and ponds, being also able to temporarily survive under arid conditions buried in the dried-out mud [26].

In a previous work dealing with evolutionary aspects of gastropod MTs including other freshwater snails of the same family (Ampullariidae), PbrMT1 and PbrMT2 were classified as unselective MTs [13]. Based on preliminary analyses and phylogenetic inferences, this work hypothesized that the MTs of freshwater snails might have lost their metalselective character during adaptation of gastropod families to freshwater habitats with low $\mathrm{Cd}$ background concentrations [13]. However, a detailed comparative characterization of the two PbrMTs providing valuable biochemical information about their metal-binding features was missing. To this end, we have thoroughly analyzed the metal-binding abilities of PbrMT1 and PbrMT2 after their recombinant production in metal-supplemented media, including a further experiment in which initially Zn(II)-loaded MT complexes were replaced by $\mathrm{Cd}(\mathrm{II})$ to assess their behavior under in vitro conditions. Our approach is based on convincing evidence that heterologous productions of MTs yield metal-MT complexes structurally and functionally equivalent to those isolated from native sources $[7,8,14,27,28]$. 
In the present study, all our preparations were characterized by UV-Vis and circular dichroism spectroscopies and mass spectrometry in order to establish the metal-binding features of the P. bridgesii MTs, providing experimental evidence to further confirm or reject the inferences made on the basis of our phylogenetic approach. This information will allow us to correlate the binding abilities of these proteins with the requirements of metal handling of $P$. bridgesii, and to speculate how the evolution of unspecific MTs might have provided an adaptive advantage to this species for tolerating variable and fluctuating metal availabilities, improving its adaptation capacity to an amphibious lifestyle.

\section{Results}

\subsection{Sequence Features of PbrMTs}

As already mentioned above, P. bridgesii is a freshwater snail belonging to the gastropod class of Caenogastropoda and specifically, to the apple snail family of Ampullariidae. The amino acid sequences of its two MTs (PbrMT1 and PbrMT2) were aligned with other gastropod MTs (Figure 1). The sequences chosen for the alignment comprise an MT from another freshwater apple snail of the same genus, Pomacea diffusa (PdiMT1) [23]; two known Cd-selective MTs from other Caenogastropoda such as the marine periwinkle Littorina littorea (LliMT) $[29,30]$, and the round-mouthed snail Pomatias elegans, a close relative of $L$. littorea, but adapted to terrestrial conditions [31]. P. diffusa is a close relative of P. bridgesii, and its PdiMT1 shows a high sequence homology to PbrMT1 and the same domain organization as PbrMT1, although the metal selectivity features of PdiMT1 are still unknown. The MTs from L. littorea (LliMT) and P. elegans (PelMT1) are Cd-selective and comprise three metal-binding domains, one C-terminal $\beta 1$ and two $\mathrm{N}$-terminal $\beta 3$ domains [23]. Additionally, shown in the alignment are two Cd-selective (CaCdMT and HpCdMT) and two $\mathrm{Cu}$-selective MTs (CaCuMT and HpCuMT) from the two terrestrial helicid snails $C$. aspersus and $\mathrm{H}$. pomatia, respectively $[7,14,32]$ (Figure 1 ). These snail species belong to the gastropod class of Heterobranchia which constitutes the sister clade to Caenogastropoda. The alignment in Figure 1 reveals the archetypal structure of gastropod MTs consisting of $\beta 3 / \beta 1$ domains, featuring cysteine motifs like $\mathrm{Cx}_{3} \mathrm{Cx}_{4}[\mathrm{CxC}] \mathrm{x}_{3-5}[\mathrm{CxC}] \mathrm{x}_{3}[\mathrm{CxC}] \mathrm{x}_{2} \mathrm{C}$ in the N-terminal $\beta 3$ domain, and $[\mathrm{CxC}] \mathrm{x}_{3-4}[\mathrm{CxC}] \mathrm{x}_{3} \mathrm{Cx}_{5-6}[\mathrm{CxC}] \mathrm{x}_{3}[\mathrm{CxC}]$ in the $\mathrm{C}$-terminal $\beta 1$ domain [23].

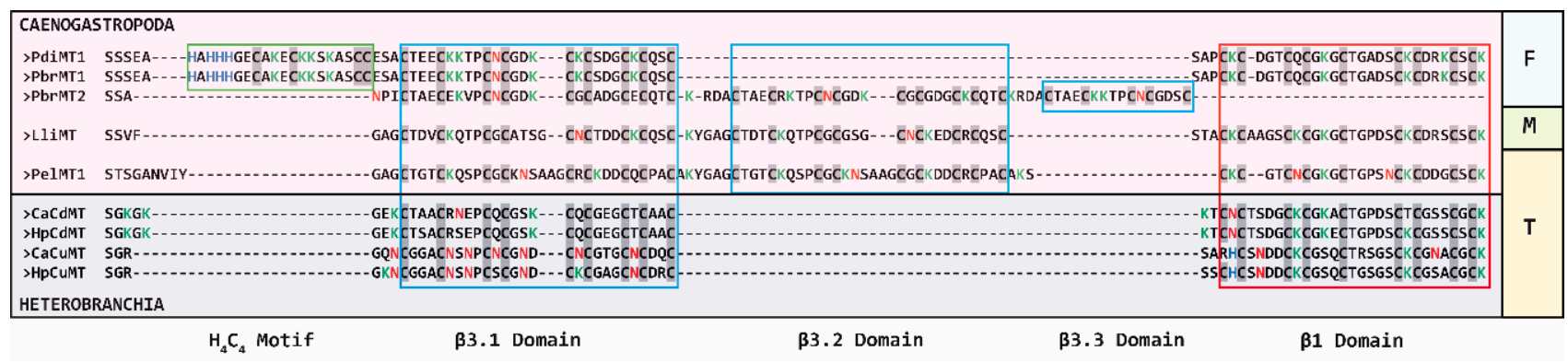

Figure 1. Amino acid alignment of P. bridgesii MTs (PbrMT1 and PbrMT2) sequences with other gastropod MTs from species of Caenogastropoda (pink background) and Heterobranchia (purple background) classes (SRA accession number/UniProt accession number): P. diffusa PdiMT1 (SRX3488051_2_SRX644696), L. littorea LliMT (Q962G0), P. elegans PelMT1 (KY646305), C. aspersus CaCdMT (A1YZ80; a.k.a. HasMT2) and CaCuMT (A2I9Y4; a.k.a. HasMT1) and H. pomatia HpCdMT (P33187; a.k.a. HpoMT2) and HpCuMT (P55947; a.k.a. HpoMT1). $\beta 3$-domains are boxed in blue, $\beta 1$-domain in red, and the $\mathrm{H}_{4} \mathrm{C}_{4}$ motif in green. Cysteines are highlighted with a grey background, histidines are colored in blue, lysines in green, and asparagines in red. Colored boxes at the right side of the alignment indicate the habitats of the selected species: in light blue for freshwater (F) habitats, in light green for marine (M) habitats, and in light brown for terrestrial (T) habitats.

Both PbrMTs show remarkable deviations from the archetypal $\beta 3 / \beta 1$ structure of most other gastropod MTs (Figure 1). PbrMT1 contains additional cysteine (C) and histidine $(\mathrm{H})$ residues in a $\mathrm{H}_{4} \mathrm{C}_{4}$ motif $\left(\mathrm{HxHHHx}_{2} \mathrm{Cx}_{3} \mathrm{Cx}_{6} \mathrm{CC}\right)$ in its $\mathrm{N}$-terminal region, also shared by PdiMT1 of $P$. diffusa from the same genus, suggesting that the $\mathrm{H}_{4} \mathrm{C}_{4}$ motif may represent a 
lineage-specific sequence divergence in some MTs of closely related ampullariid freshwater snails. PbrMT2 possesses two tandem duplications (one full-length and one partial) of the $\beta 3$ domain, but it has lost its $\beta 1$ domain. Therefore, the domain structure of PbrMT2 is $\beta 3.1 / \beta 3.2 / \beta 3.3$ (Figure 1). PbrMT1 and PbrMT2 contain, therefore, an extra number of Cys with respect to the archetypal gastropod MTs, probably conferring to them the capability of binding additional metal ions.

Sequence analysis also revealed that the number of lysine residues $(K)$ is higher in PbrMT1 than in PbrMT2 (14 vs. 9), which in turn contains more asparagine residues (N) compared to PbrMT1 (4 vs. 1). These differences may be significant because previous studies had suggested a connection between the K:N ratio of gastropod MTs and their kind of metal preference [12,22]. Hence, snail MTs with a preponderance of K over N residues would have a binding preference for divalent metals such as $\mathrm{Zn}(\mathrm{II})$ and $\mathrm{Cd}(\mathrm{II})$, whereas MTs with a predominance of $\mathrm{N}$ over $\mathrm{K}$ would exhibit a $\mathrm{Cu}$-thionein character $[12,19,22]$.

\subsection{Production of Metal-PbrMT Complexes}

To explore the metal selectivity features of the two P. bridgesii MTs, we studied the formation of metal-PbrMT1 and metal-PbrMT2 complexes by the proteins heterologously expressed in E. coli and grown in media supplemented with $\mathrm{Cu}(\mathrm{II}), \mathrm{Cd}(\mathrm{II})$ or $\mathrm{Zn}$ (II) salts. In order to confirm the identity of the proteins recombinantly produced, apo-PbrMT1 and apo-PbrMT2 forms were obtained from the respective Zn-PbrMT productions under acidic conditions ( $\mathrm{pH}$ 2.4), and analyzed by ESI-MS. The experimental masses of PbrMT1 and PbrMT2 (9235.5 Da and 8973.3 Da) were coincident with the theoretical masses predicted (9235.51 Da and 8975.20 Da) (Figure 2), ascertaining that the major proportions of the produced proteins corresponded in their masses with the two respective PbrMTs. Here, it should be noticed that recombinant proteins contain two additional amino acids (GS) at their N-term, and therefore the theoretical masses correspond to full length PbrMT1 and PbrMT2 plus those two amino acids. Moreover, in the $\mathrm{Zn}$-supplemented productions, it has to be noted that an additional minor species with an extra mass of 162 Da was detected for PbrMT2. This minor species, named Apo'-PbrMT2 (Figure 2B), did not disappear when acidifying to $\mathrm{pH} \mathrm{1,} \mathrm{and} \mathrm{it} \mathrm{was} \mathrm{not} \mathrm{found} \mathrm{neither} \mathrm{in} \mathrm{PbrMT1} \mathrm{nor} \mathrm{in} \mathrm{the} \mathrm{PbrMT2}$ productions in media supplemented with $\mathrm{Cd}(\mathrm{II})$ or with $\mathrm{Cu}$ (II). Preliminary studies suggest that Apo'-PbrMT2 is a minor form artefactually produced only in the PbrMT2 productions with $\mathrm{Zn}$ (II) ions, and thereby not affecting the overall characterization of the metal-MTs complexes.

\subsection{Zn(II) Binding Abilities of the PbrMT Isoforms}

Both PbrMTs rendered mixtures of several species when synthesized in culture media enriched with $\mathrm{ZnCl}_{2}$ (Table 1; Figure 3). In particular, these mixtures consisted of $\mathrm{Zn}_{8^{-}}$ (major) and $\mathrm{Zn}_{7}-$ complexes for PbrMT1, and $\mathrm{Zn}_{7}$ - (major), $\mathrm{Zn}_{8}$ - and $\mathrm{Zn}_{6}$ - complexes for PbrMT2. Concordantly, these results match those obtained by ICP-AES (Table 1), and although PbrMT2 has one Cys more than PbrMT1 (23 vs. 22 Cys), both MTs rendered similar metallated species. However, and despite the degree of heterogeneity in speciation of the Zn-PbrMT1, preparation is lower than that of Zn-PbrMT2, the latter shows a higher folding degree with an exciton coupling at ca. $240 \mathrm{~nm}$ in the CD spectra in front of the simple Gaussian band at the same wavelength recorded for the Zn-PbrMT1 preparation (Figure 3C). 

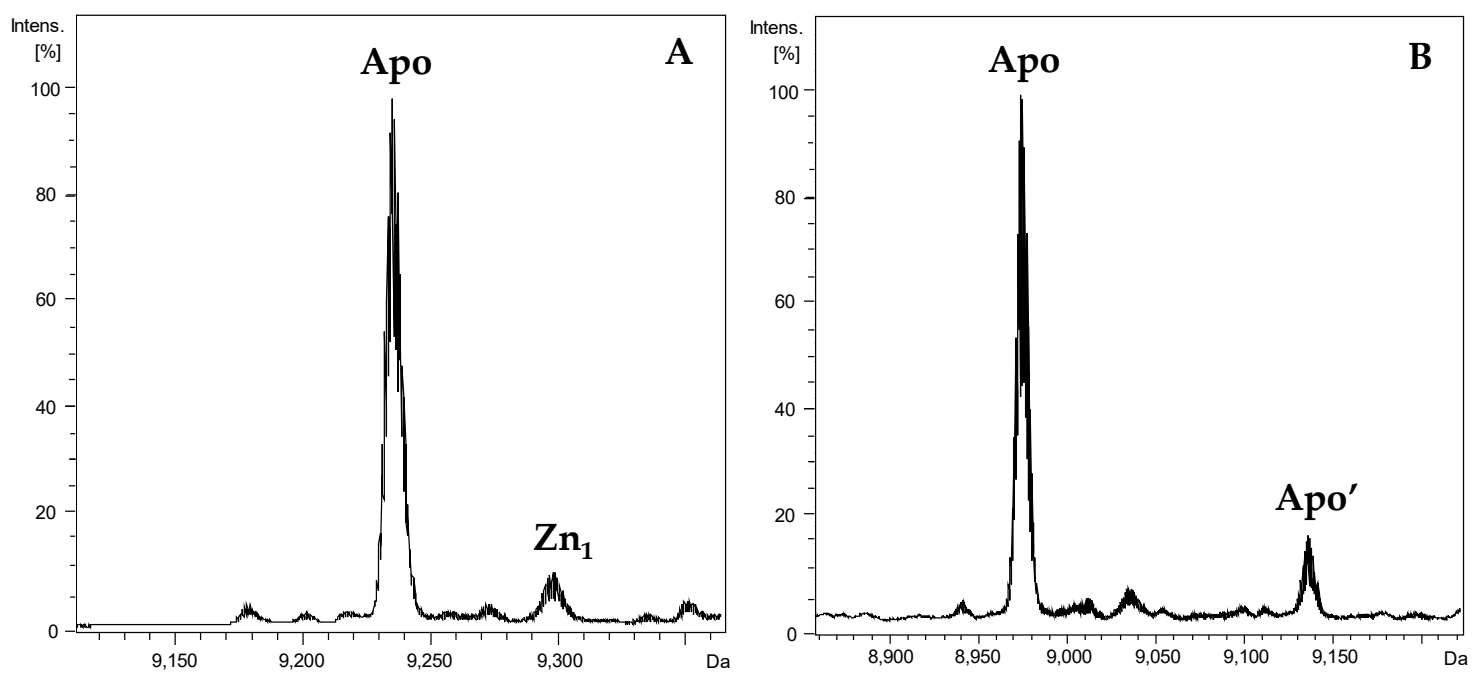

Figure 2. Deconvoluted ESI-MS spectra recorded at acidic conditions (pH 2.4) of (A) apo-PbrMT1 and (B) apo-PbrMT2 from the Zn-MT productions.

Table 1. Metal-to-protein ratios found by ICP-AES in the recombinantly produced Zn(II)-, Cd(II)- and Cu(I)-PbrMT1 and PbrMT2 preparations. ESI-MS data were recorded at neutral $\mathrm{pH}$ and are shown in several figures along this work.

\begin{tabular}{|c|c|c|c|c|}
\hline MT & $\begin{array}{c}\text { Supplemented } \\
\text { Metal }\end{array}$ & $\begin{array}{c}\text { M/Protein } \\
\text { (Conventional) }\end{array}$ & $\begin{array}{l}\text { M/Protein b } \\
\text { (Acidic) }\end{array}$ & ESI-MS Results c,d \\
\hline \multirow{3}{*}{$\begin{array}{l}\text { PbrMT1 } \\
\text { (22 Cys) }\end{array}$} & $\mathrm{Zn}$ & $7.4 \mathrm{Zn}$ & n.m. & $\mathrm{Zn}_{8}-$ (major) $>\mathrm{Zn}_{7^{-}}$ \\
\hline & $\mathrm{Cd}$ & $5.3 \mathrm{Cd}$ & $8.6 \mathrm{Cd}$ & $\mathrm{Cd}_{8^{-}} \sim \mathrm{Cd}_{7} \mathrm{~S}_{2^{-}}($major $)>\mathrm{Cd}_{7^{-}}$ \\
\hline & $\mathrm{Cu}$ & $2.3 \mathrm{Zn} ; 12.4 \mathrm{Cu}$ & n.m. & $\mathrm{M}_{8^{-}}$to $\mathrm{M}_{13^{-}}$ \\
\hline \multirow{3}{*}{$\begin{array}{l}\text { PbrMT2 } \\
\text { (23 Cys) }\end{array}$} & $\mathrm{Zn}$ & $6.4 \mathrm{Zn}$ & $7.1 \mathrm{Zn}$ & $\mathrm{Zn}_{7^{-}}($major $)>\mathrm{Zn}_{8^{-}}>\mathrm{Zn}_{6^{-}}>\mathrm{Zn}_{6^{-}}>\mathrm{Zn}_{7}{ }^{*}$ \\
\hline & $\mathrm{Cd}$ & $6.9 \mathrm{Cd}$ & $9.0 \mathrm{Cd}$ & $\begin{array}{c}\text { d-Cd }{ }_{18} \text { S- to d-Cd } \mathrm{Cd}_{22} \mathrm{~S}- \\
\mathrm{Cd}_{8}-(\text { major })>\mathrm{Cd}_{9^{-}}\end{array}$ \\
\hline & $\mathrm{Cu}$ & $16.4 \mathrm{Cu}$ & n.m. & $\mathrm{Cu}_{9^{-}}$to $\mathrm{Cu}_{17^{-}}$ \\
\hline
\end{tabular}

\footnotetext{
a Metal-to-protein ratios obtained from conventional ICP. $\mathrm{Zn}, \mathrm{Cd}$ and $\mathrm{Cu}$ were measured in all cases but only those results different than zero are shown. ${ }^{b}$ Metal-to-protein ratio obtained from acidic ICP. $\mathrm{Zn}, \mathrm{Cd}$, and $\mathrm{Cu}$ were measured in all cases but only those results different than zero are shown. n.m. stands for "not measured". ${ }^{c} \mathrm{~d}$ stands for dimeric species. ${ }^{\mathrm{d}}$ species with * correspond to metal complexes formed by apo'-PbrMT2.
}

\subsection{Cd(II) Binding Abilities of the PbrMT Isoforms}

The recombinant synthesis of PbrMT1 and PbrMT2 in cultures supplemented with $\mathrm{CdCl}_{2}$ also rendered a mixture of species (Figure 4), as in the case of the $\mathrm{Zn}$ productions. The difference between the conventional ICP values and the acidic ones in both productions (Table 1), as well as the presence of $\mathrm{CD}$ bands with maxima at wavelengths higher than $255 \mathrm{~nm}$ (Figure 4D) clearly indicate the presence of additional Cd-S ${ }^{2-}$ chromophores $[3,33]$. On the one side, PbrMT1 rendered $\mathrm{Cd}_{8}-$ and $\mathrm{Cd}_{7} \mathrm{~S}_{2}-$ as major species, together with minor $\mathrm{Cd}_{7}$-PbrMT1 (Figure 4A). On the other hand, PbrMT2 yielded dimeric species ranging from $\mathrm{d}-\mathrm{Cd}_{18} \mathrm{~S}$ - to d-Cd $\mathrm{Cd}_{22} \mathrm{~S}-\mathrm{PbrMT} 2$ (Figure $4 \mathrm{~B}$ ), together with a mixture of monomeric $\mathrm{Cd}_{8}$ and $\mathrm{Cd}_{9}$-PbrMT2 (Figure $4 \mathrm{C}$ ) species. 


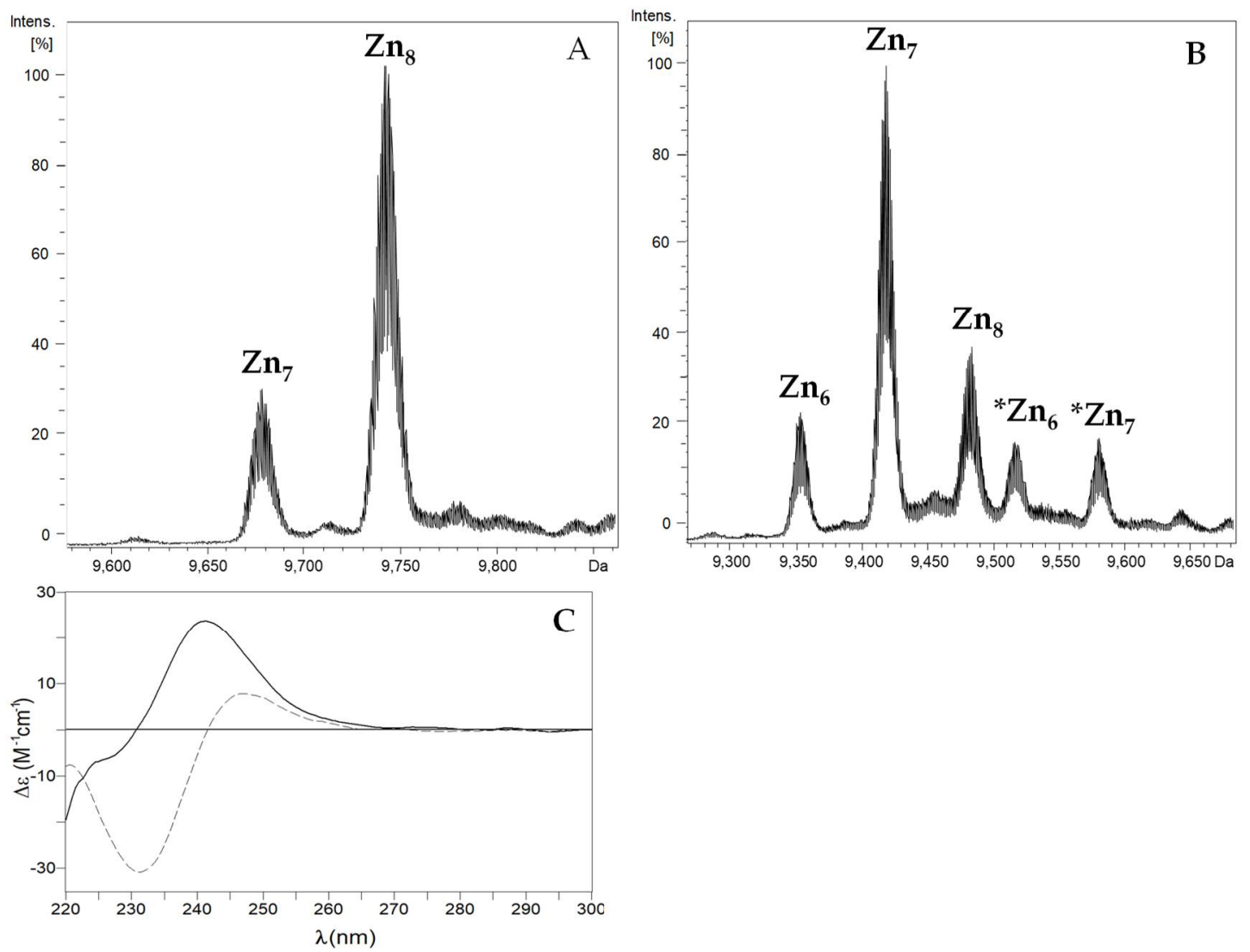

Figure 3. Deconvoluted ESI-MS spectra of the recombinant productions of (A) Zn-PbrMT1 and (B) Zn-PbrMT2 at neutral pH. (C) CD spectra of Zn-PbrMT1 (solid) and Zn-PbrMT2 (dashed) productions. Species with * correspond to metal complexes formed by apo'-PbrMT2.

These results already point out that these two MTs are clearly non-Cd-selective and at the same time, barely reveal any differences in their behavior towards $\mathrm{Cd}(\mathrm{II})$. To further investigate the $\mathrm{Cd}(\mathrm{II})$ binding capabilities of these two MTs, their in vitro $\mathrm{Cd}(\mathrm{II})$-complexes were obtained by adding $\mathrm{Cd}(\mathrm{II})$ aliquots to both $\mathrm{Zn}$-PbrMT preparations. As shown in Figure S1 and Table 2, Zn-PbrMT1 shows a gradual non-cooperative replacement of Zn(II) by $\mathrm{Cd}(\mathrm{II})$. In terms of $\mathrm{CD}$ absorptions, the first $6 \mathrm{Cd}$ (II) equivalents evoked the same effect in the protein folding, leading to the replacement of the initial Gaussian band at ca. $240 \mathrm{~nm}$ to a positive $\mathrm{CD}$ absorption centered at ca. $265 \mathrm{~nm}$, very similar to the signal recorded for the recombinant Cd-PbrMT1 preparation (Figure S1E). Further additions of $\mathrm{Cd}$ (II) only led to small variations in the $\mathrm{CD}$ and $\mathrm{UV}$-vis envelopes (Figure $\mathrm{S1}$ ), suggesting that after 6-7 $\mathrm{Cd}$ (II) equivalents added only slight modifications in the structuration of the Cd-PbrMT1 species take place without the incorporation of further Cd(II) ions. The ESI-MS data of this experiment (Figure S2; Table 2) show a subsequent $\mathrm{Zn} / \mathrm{Cd}$ replacement from the initial preparation, containing $\mathrm{Zn}_{8}$ - and $\mathrm{Zn}_{7}-\mathrm{PbrMT1}$ species, to mainly major $\mathrm{Zn}_{1} \mathrm{Cd}_{7}$ - and $\mathrm{Cd}_{7}-\mathrm{PbrMT1}$ after the addition of $7 \mathrm{Cd}$ (II) which remain unaltered in solution for $10 \mathrm{Cd}(\mathrm{II})$ added, without reaching the $\mathrm{Cd}_{8}$ - major species achieved in the recombinant preparation. 

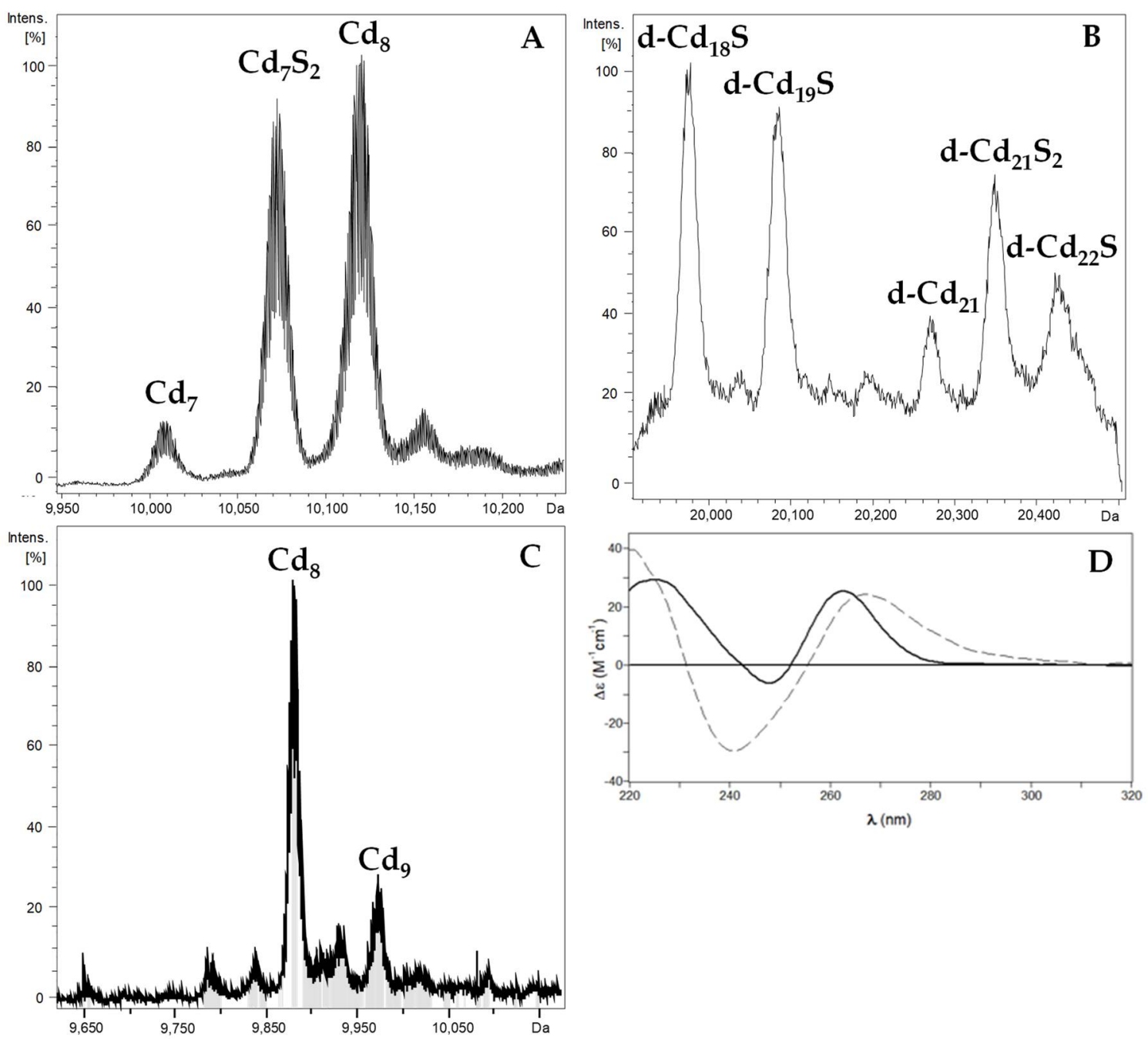

Figure 4. In vivo Cd(II) binding assessment of PbrMT1 and PbrMT2. Deconvoluted ESI-MS spectra of (A) Cd-PbrMT1 and $(\mathbf{B}, \mathbf{C}) \mathrm{Cd}-\mathrm{PbrMT} 2$ productions. Dimeric species in the Cd-PbrMT2 production spectrum are marked as "d-“. (D) CD spectra of Cd-PbrMT1 (solid) and of Cd-PbrMT2 (dashed) productions.

Table 2. Species detected by ESI-MS during the addition of Cd(II) to the Zn-PbrMT1 preparation at pH 7.0. The corresponding ESI-MS spectra are shown in Figure S2.

\begin{tabular}{|c|c|c|c|c|c|c|c|}
\hline \multirow{2}{*}{$\mathrm{Zn}+\mathrm{Cd}$} & & \multicolumn{6}{|c|}{ Cd(II) Equivalents } \\
\hline & & 0 & 1 & 3 & 5 & 7 & 10 \\
\hline 7 & $\mathrm{Zn}_{7}-\mathrm{PbrMT} 1$ & $\bullet$ & $\boldsymbol{*}$ & & & & \\
\hline 8 & $\mathrm{Zn}_{8}-\mathrm{PbrMT} 1$ & $\boldsymbol{v}$ & $\bullet$ & & & & \\
\hline 8 & $\mathrm{Zn}_{7} \mathrm{Cd}_{1}-\mathrm{PbrMT} 1$ & & $\checkmark$ & & & & \\
\hline 7 & $\mathrm{Zn}_{6} \mathrm{Cd}_{1}-\mathrm{PbrMT} 1$ & & $\bullet$ & & & & \\
\hline 8 & $\mathrm{Zn}_{6} \mathrm{Cd}_{2}-\mathrm{PbrMT} 1$ & & $\bullet$ & $\boldsymbol{*}$ & & & \\
\hline 8 & $\mathrm{Zn}_{5} \mathrm{Cd}_{3}-\mathrm{PbrMT} 1$ & & $\boldsymbol{x}$ & $\checkmark$ & & & \\
\hline 8 & $\mathrm{Zn}_{4} \mathrm{Cd}_{4}-\mathrm{PbrMT} 1$ & & & $\checkmark$ & & & \\
\hline 8 & $\mathrm{Zn}_{3} \mathrm{Cd}_{5}-\mathrm{PbrMT} 1$ & & & $\bullet$ & $\boldsymbol{v}$ & & \\
\hline 8 & $\mathrm{Zn}_{2} \mathrm{Cd}_{6}-\mathrm{PbrMT} 1$ & & & $\boldsymbol{*}$ & $\checkmark$ & & \\
\hline 7 & $\mathrm{Zn}_{1} \mathrm{Cd}_{6}-\mathrm{PbrMT} 1$ & & & & $\bullet$ & $\boldsymbol{x}$ & $\boldsymbol{x}$ \\
\hline 8 & $\mathrm{Zn}_{1} \mathrm{Cd}_{7}-\mathrm{PbrMT} 1$ & & & & $\bullet$ & $\checkmark$ & $\checkmark$ \\
\hline 7 & $\mathrm{Cd}_{7}-\mathrm{PbrMT} 1$ & & & & & $\boldsymbol{*}$ & $\bullet$ \\
\hline
\end{tabular}

$\boldsymbol{V}$ denotes major species, $\bullet$ denotes intermediate species, $\boldsymbol{x}$ denotes minor species. The terms "major", "intermediate" and "minor" species refer to their signal intensity in the corresponding MS spectra. 
The Zn/Cd displacement carried out on the Zn-PbrMT2 preparation (Figure S3; Table 3) shows a different pattern from that observed in Zn-PbrMT1, as expected if considering their different amino acid composition (Figure 1) and the speciation of their respective $\mathrm{Zn}$ (II) preparations (Figure 3). The addition of Cd(II) to Zn-PbrMT2 provoked a complex progression from an initial CD spectrum showing the characteristic exciton coupling band at ca. $240 \mathrm{~nm}$ of certain $\mathrm{Zn}-\mathrm{MT}$ complexes, to another exciton coupling at ca. $245 \mathrm{~nm}$ after $10 \mathrm{Cd}$ (II) equivalents added. This final stage, as expected, is different from that recorded for the recombinant Cd-PbrMT2 sample (Figure S3F) due to the content of labile $\mathrm{S}^{2-}$ ions of the latter which contribute to the signal in the $280-300 \mathrm{~nm}$ range. UV-vis differences between additions at the latter stages of the experiment showed barely any differences between chromophores, suggesting that the protein did not accept extra metal ions (Figure S3D,E).

Table 3. Species detected by ESI-MS during the addition of Cd(II) to the Zn-PbrMT2 preparation at pH 7.0. The corresponding ESI-MS spectra are shown in Figure S4.

\begin{tabular}{|c|c|c|c|c|c|c|c|}
\hline \multirow{2}{*}{$\mathrm{Zn}+\mathrm{Cd}$} & & \multicolumn{6}{|c|}{ Cd(II) Equivalents } \\
\hline & & 0 & 2 & 4 & 6 & 8 & 10 \\
\hline 7 & $\mathrm{Zn}_{7}-\mathrm{PbrMT} 2$ & $\checkmark$ & & & & & \\
\hline 8 & $\mathrm{Zn}_{8}-\mathrm{PbrMT} 2$ & $\bullet$ & & & & & \\
\hline 8 & $\mathrm{Zn}_{6}{ }^{*}-\mathrm{PbrMT} 2$ & $\bullet$ & & & & & \\
\hline 9 & $\mathrm{Zn}_{7}^{*-P b r M T 2}$ & $\boldsymbol{x}$ & $\bullet$ & & & & \\
\hline 8 & $\mathrm{Zn}_{5} \mathrm{Cd}_{3}-\mathrm{PbrMT} 2$ & & $\checkmark$ & & & & \\
\hline 7 & $\mathrm{Zn}_{4} \mathrm{Cd}_{3}-\mathrm{PbrMT} 2$ & & $\bullet$ & & & & \\
\hline 8 & $\mathrm{Zn}_{4} \mathrm{Cd}_{4}$-PbrMT2 & & $\bullet$ & $\bullet$ & & & \\
\hline 8 & $\mathrm{Zn}_{3} \mathrm{Cd}_{5}-\mathrm{PbrMT} 2$ & & $\boldsymbol{x}$ & $\checkmark$ & $\boldsymbol{x}$ & & \\
\hline 8 & $\mathrm{Zn}_{2} \mathrm{Cd}_{6}-\mathrm{PbrMT} 2$ & & & $\bullet$ & $\bullet$ & & \\
\hline 8 & $\mathrm{Zn}_{1} \mathrm{Cd}_{7}-\mathrm{PbrMT} 2$ & & & $\bullet$ & $\checkmark$ & $\bullet$ & $\boldsymbol{*}$ \\
\hline 9 & $\mathrm{Zn}_{1} \mathrm{Cd}_{8}-\mathrm{PbrMT} 2$ & & & & $\bullet$ & $\bullet$ & $\bullet$ \\
\hline 8 & $\mathrm{Cd}_{8}-\mathrm{PbrMT} 2$ & & & & $\nu$ & $\nu$ & $\checkmark$ \\
\hline 10 & $\mathrm{Zn}_{1} \mathrm{Cd}_{9}-\mathrm{PbrMT} 2$ & & & & & $\boldsymbol{*}$ & $\bullet$ \\
\hline 9 & $\mathrm{Cd}_{9}-\mathrm{PbrMT} 2$ & & & & $\boldsymbol{*}$ & $\boldsymbol{*}$ & $\bullet$ \\
\hline 10 & $\mathrm{Cd}_{10}-\mathrm{PbrMT} 2$ & & & & & & $\bullet$ \\
\hline
\end{tabular}

$\boldsymbol{V}$ denotes major species, $\bullet$ denotes intermediate species, $\mathbf{x}$ denotes minor species. The terms "major", "intermediate" and "minor" species refer to their signal intensity in the corresponding MS spectra.

It is remarkable that, at after $6 \mathrm{Cd}$ (II) equivalents added, PbrMT2 renders not only the same $\mathrm{Zn}_{1} \mathrm{Cd}_{7}$ - species as PbrMT1 but also $\mathrm{Cd}_{8}$-PbrMT2. This last species is maintained as one of the important peaks during the whole metal-displacement experiment, as can be seen in the ESI-MS (Table 3; Figure S4). Additionally, unlike PbrMT1, PbrMT2 reaches, at the latter stages, high metallated homonuclear species such as $\mathrm{Cd}_{9}$ - and $\mathrm{Cd}_{10}$-PbrMT2. These results are in agreement with those from the recombinant productions in E. coli and suggest that, although none of the PbrMTs are specifically adapted to capture $\mathrm{Cd}(\mathrm{II})$, PbrMT2 can bind more Cd(II) than PbrMT1, in accordance with the former's higher content in Cys residues.

\subsection{Cu(I) Binding Abilities of the PbrMTs}

The recombinant synthesis of both PbrMT peptides in Cu-supplemented media rendered always a mixture of species (Figure 5), but important differences among both proteins were observed. The ICP-AES results of both Cu-supplemented PbrMT preparations (Table 1) show that, while PbrMT1 renders heterometallic Zn,Cu-species, PbrMT2 yields homometallic $\mathrm{Cu}(\mathrm{I})$ species. Moreover, a higher $\mathrm{Cu}$ content was detected for PbrMT2 $(16.4 \mathrm{Cu})$, as it was expected if considering that this MT has one more Cys residue than PbrMT1 (12.4 Cu and 2.3 Zn). Consistent with these results, ESI-MS spectra reveal the presence of various metallated species, ranging from $\mathrm{M}_{9}$ - to $\mathrm{M}_{13}$-PbrMT1 (Figure 5A), while for PbrMT2 an intense peak of $\mathrm{Cu}_{15}$-PbrMT2 was detected above the minor species ranging from $\mathrm{Cu}_{11}$ - to $\mathrm{Cu}_{17}-\mathrm{PbrMT2}$ (Figure $5 \mathrm{~B}$ ). Despite the speciation differences observed, their 
CD spectra of the two MT preparations are quite similar (Figure 5C), depicting very faint absorption bands that denote a low degree of protein folding about the metal ions.
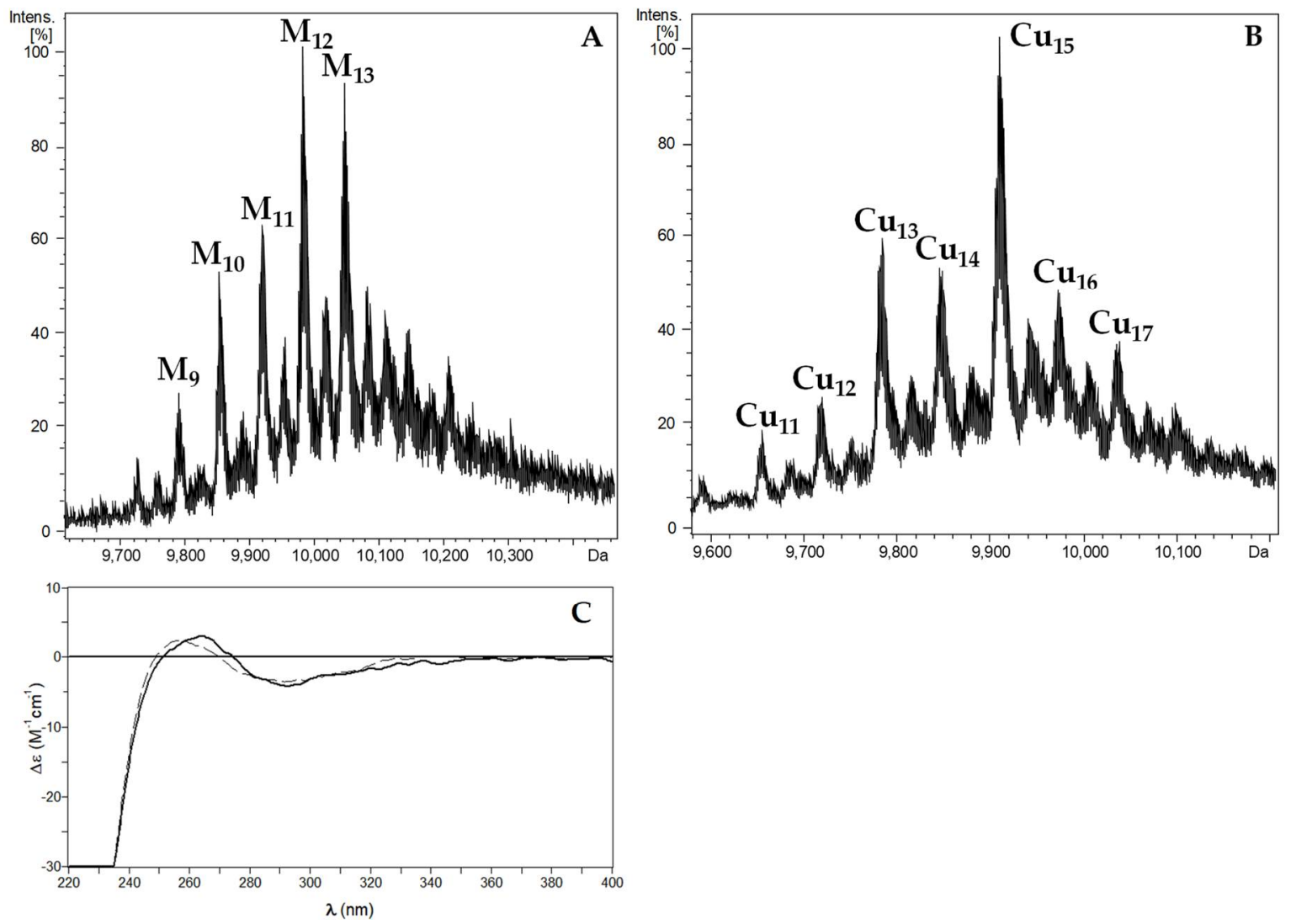

Figure 5. In vivo $\mathrm{Cu}(\mathrm{I})$ binding assessment of recombinant PbrMT1 and PbrMT2. Deconvoluted ESI-MS spectra of (A) Cu-PbrMT1 and (B) Cu-PbrMT2 productions. (C) CD spectra of PbrMT1 (solid) and of PbrMT2 (dashed) productions.

\section{Discussion}

Sequence analyses reveal unconventional primary structures for both multi-modular MTs of $P$. bridgesii, very divergent from that of the archetypal $\beta_{3} / \beta_{1}$ MT form of other gastropods (Figure 1). On one hand, PbrMT1 has an additional domain with a $\mathrm{H}_{4} \mathrm{C}_{4}$ motif in its N-terminal region, which has been also found in other gastropod MTs [23], all of them belonging to the freshwater family of Ampullariidae (informal group of Architaenioglossa) form the gastropod clade of Caenogastropoda. It is assumed that a lineage-specific event may have added the $\mathrm{H}_{4} \mathrm{C}_{4}$ motif to the N-terminus of an ancestral Architaenioglossan MT duplicate. This motif increases the number of potential metal-coordinating amino acids (histidines and cysteines), and thereby it could also increase its binding capacity for metal ions. In fact, the recombinant $\mathrm{Zn}$ (II)- and $\mathrm{Cd}(\mathrm{II})$-PbrMT productions always rendered mixtures of mainly $\mathrm{M}_{7}$ - and $\mathrm{M}_{8}$-PbrMT species $(\mathrm{M}=\mathrm{Zn}$ or $\mathrm{Cd})$, which represents up to $33 \%$ of increased capacity with respect to the $\mathrm{M}_{6}$-MT species rendered by archetypal gastropod $\beta_{3} / \beta_{1}$ MTs [23]. However, metal binding sites including His residues are known for their preference for $\mathrm{Zn}$ over $\mathrm{Cd}$, so this $\mathrm{H}_{4} \mathrm{C}_{4}$ motif may intervene in metal-selectivity features of PbrMT1 [33-35]. Overall, we found this peculiar motif extremely interesting, and for that reason, the biochemical properties of this $\mathrm{H}_{4} \mathrm{C}_{4}$ motif in ampullariid MTs and its possible role in modifying metal selectivity features of PbrMT1 will be widely clarified and discussed in a separate study.

On the other hand, structural evolution has led PbrMT2 to lose the C-terminal $\beta 1$ domain and to tandem-duplicate the $\beta 3$ domain. These modifications increase the overall number of coordinating cysteines from 18 in the conventional gastropod $\beta_{3} / \beta_{1}$ MTs [23] to 
23, implying a higher number of divalent metal ions that these MTs may be able to bind compared to other gastropod MTs [13]. Our results clearly revealed an increased metalbinding capacity for PbrMT2, ranging from the $\mathrm{M}_{6}-\mathrm{MT}$ species rendered by archetypal gastropod MTs to $\mathrm{M}_{8}$-PbrMT2 complexes. Other known mollusk MTs with similarly high Cys contents, such as Mytilus galloprovincialis MT-10 (21 Cys) and MT-20 (23 Cys), were recovered binding $7 \mathrm{Cd}$ (II) ions [36,37]. Surprisingly, the presence of 22-23 Cys residues in the $P$. bridgesii metallothioneins provoked the binding of one more $\mathrm{M}(\mathrm{II})$ ion, in comparison with the mentioned MTs of Mytilus, to render $\mathrm{M}_{8}$-species. Moreover, the presence of labile sulfide ligands in the Cd-preparations of both PbrMTs resulted in the absence of a clearly defined $\mathrm{M}(\mathrm{II})$-thionein character $(\mathrm{M}=\mathrm{Zn}, \mathrm{Cd})$ for these MTs. Interestingly, the analysis of the CD spectra revealed that the Zn-PbrMT2 (major Zn 7 -species, heterogenous speciation) preparation shows an exciton coupling centered at $240 \mathrm{~nm}$ which contrasts with the Gaussian band at the same wavelength recorded for the Zn-PbrMT1 (major $\mathrm{Zn}_{8^{-}}$and minor $\mathrm{Zn}_{7}$-complexes) production. This probably points out to a formation of more compact clusters with $7 \mathrm{Zn}$ (II) ions in PbrMT2 than with 8 Zn(II) ions in PbrMT1. Overall, our results support that the multi-modular MTs of $P$. bridgesii have significantly diverged from the archetypal $\beta_{3} / \beta_{1}$ gastropod MT variants not only with respect to their primary structure, but also by acquiring a higher metal-binding capacity than the standard gastropod MTs.

Complementary to the data from recombinant productions of metal-MT complexes, the $\mathrm{Zn}$-by-Cd in vitro replacement carried out in both Zn-preparations proceeded similarly. The initial Zn-species led, by a gradual non-cooperative replacement, to final Cd-species with similar CD profiles as those observed in the recombinant $\mathrm{Cd}$-productions. Proba$\mathrm{bly}$, the absence of the additional $\mathrm{S}^{2-}$ ligands in the $\mathrm{Zn}$ (II)-preparations observed in the recombinant $\mathrm{Cd}$ (II) samples could be the main reason for the recording of different $\mathrm{CD}$ signals at the end of both $\mathrm{Cd}(\mathrm{II})$ titrations. These $\mathrm{Zn} / \mathrm{Cd}$ replacement reaction in both proteins revealed that PbrMT1 possesses a higher Zn(II)-thionein character than PbrMT2, and that PbrMT2 exhibits a higher Cd(II) than Zn(II) specificity compared to PbrMT1. While Zn-PbrMT1 productions are reluctant to fully exchange the initial Zn(II), even after the addition of $10 \mathrm{Cd}$ (II) equivalents, Zn-PbrMT2 preparations easily release their Zn(II) metal ions at the early stages of the displacement experiment and render highly metallated homometallic $\mathrm{Cd}(\mathrm{II})$-species at the late stages. With regards to $\mathrm{Cu}(\mathrm{I})$ binding, the most remarkable difference between the two PbrMTs has been the significant presence of $\mathrm{Zn}$ (II) in the $\mathrm{Cu}(\mathrm{I})$-PbrMT1 production (Table 1), which reinforces the fact that PbrMT1 shows a stronger Zn-thionein character than PbrMT2.

Overall, our analyses have revealed that the two PbrMTs do not exhibit strong metal specificities for any of the tested metals, probably because their overall primary structure and special Cys pattern seem to make them incapable of forming unique homometallic $\mathrm{Zn}$ - Cd- or Cu-metallated species. We have therefore experimentally demonstrated that both proteins are unspecific, but with similar although not identical biochemical features. PbrMT1 exhibits a more pronounced Zn(II)-thionein character, while PbrMT2 shows a more explicit $\mathrm{Cu}(\mathrm{I})$-thionein character, which questions the possibility to predict the metal preference of gastropod MTs solely based on sequence features such as the K:N ratios. Our results also address an important aspect in the evolution of metal preferences of gastropod MTs. It has been hypothesized that the ancestral MT of Caenogastropoda might have been Cd-selective $[13,23]$. Our results imply the loss of the metal-binding specificity during the evolutionary adaptation to freshwater habitats in the lineage of $P$. bridgesii of the Ampullariidae family of Caenogastropoda. It can be argued that due to the low cadmium background levels in the freshwater habitats in which apple snails live [13], the selective pressure for maintaining Cd-selective MTs was no longer effective, leading therefore to the evolution of unspecific MTs. Our results, together with previous studies performed with living snails [38], suggest that the evolution of the two PbrMTs might reflect the needs of $P$. bridgesii to adapt to environmental conditions of metal-poor freshwater habitats, paired with fluctuating availabilities of metal ions due to its amphibious lifestyle. The results in 
P. bridgesii remind some of our previous findings in B. glabrata, a freshwater air-breathing snail of the clade of Hygrophila that belongs to the gastropod class of Heterobranchia, the sister class to Caenogastropoda. The MT of B. glabrata, too, has lost its Cd selectivity during adaptation of ancestral Hygrophila to freshwater habitats [13,22]. Apparently, this has also happened to PbrMT1 and PbrMT2 of P. bridgesii.

\section{Materials and Methods}

\subsection{Cloning Pomacea bridgesii Metallothioneins for Heterologous Expression}

Following an already established methodology in our groups [7,39], cDNAs of PbrMT1 and PbrMT2 (GenBank No. KY963504.1 and KY963505 [13]) were synthesized by Integrated DNA Technologies Company (Coralville, IA, USA). BamHI and XhoI restriction sites and 6 or 7 additional $5^{\prime}$-nucleotides were added to both cDNA ends to facilitate the cloning processes. Each synthetic cDNA was PCR-amplified in a $25 \mu \mathrm{L}$ PCR mixture using Expand High Fidelity PCR system (Roche, Penzberg, Upper Bavaria, Germany) with a common forward primer (5'-TTTTATTGGATCCATGTCTTC- $3^{\prime}$ for both PbrMT1 and PbrMT2) and a reverse primer specific for each MT (5'-ATTTTTCTCGAGTCACTTGC-3' for PbrMT1, and 5'-ATTTTTCTCGAGTCAGCAACTG-3' for PbrMT2). PCR conditions for both MT genes were as follows: an initial denaturation step at $94{ }^{\circ} \mathrm{C}$ for $5 \mathrm{~min}$ was followed by 25 cycles at $94{ }^{\circ} \mathrm{C}$ for $30 \mathrm{~s}, 55^{\circ} \mathrm{C}$ for $30 \mathrm{~s}$ and $72{ }^{\circ} \mathrm{C}$ for $30 \mathrm{~s}$, and a final extension step at $72{ }^{\circ} \mathrm{C}$ for $7 \mathrm{~min}$. PCR bands with the expected size were cut and purified with the GenElute ${ }^{\mathrm{TM}}$ Gel Extraction Kit (Sigma-Aldrich, St. Louis, MO, USA) following the manufacturer's instructions. PCR products were digested by BamHI and XhoI enzymes, cloned into BamHI-XhoI digested pGEX-4T-1 expression vector (GE Healthcare, Chicago, IL, USA) with the DNA Ligation kit 2.1 (Takara Bio Inc., Shimogyo-ku, Kyoto, Japan), and transformed into the E. coli DH5 $\alpha$ strain.

Plasmid DNA was purified from bacteria cultures using the GeneElute ${ }^{\mathrm{TM}}$ Plasmid Miniprep Kit (Sigma-Aldrich), screened for insert presence by digestion with ScaI enzyme, and sequenced at the Scientific and Technological Centers of the University of Barcelona, using the Big Dye Terminator v3.1 Cycle Sequencing Kit (Applied Biosystems, Waltham, MA, USA) in an automatic sequencer (ABIPRISM 310, Applied Biosystems). DNA from each recombinant PbrMT-pGEX plasmid was used to transform E. coli BL21 strain, a protease-deficient strain used for heterologous protein expression.

\subsection{Production and Purification of Recombinant Metal-PbrMT Complexes}

For production of recombinant metal-PbrMT complexes, $500 \mathrm{~mL}$ of LB medium with $100 \mu \mathrm{g} / \mathrm{mL}$ ampicillin were inoculated with E. coli BL21 cells transformed with the PbrMT1pGEX or PbrMT2-pGEX recombinant plasmids. After overnight growth at $37^{\circ} \mathrm{C} / 250 \mathrm{rpm}$, bacterial cultures were used to inoculate $5 \mathrm{~L}$ of fresh LB-100 $\mu \mathrm{g} / \mathrm{mL}$ ampicillin medium. MT expression was induced with $100 \mu \mathrm{M}$ isopropyl- $\beta$-D-thiogalactopyranoside (IPTG) for $3 \mathrm{~h}$ at $37^{\circ} \mathrm{C} / 250 \mathrm{rpm}$. After the first $30 \mathrm{~min}$ of induction, cultures were supplemented with $\mathrm{ZnCl}_{2}(300 \mu \mathrm{M}), \mathrm{CdCl}_{2}(300 \mu \mathrm{M})$, or $\mathrm{CuSO}_{4}(500 \mu \mathrm{M})$ to generate metal-PbrMT complexes. Cells were harvested by centrifugation for $5 \mathrm{~min}$ at $9100 \times g(7700 \mathrm{rpm})$, and bacterial pellets were suspended in $125 \mathrm{~mL}$ of ice-cold PBS $\left(1.4 \mathrm{M} \mathrm{NaCl}, 27 \mathrm{mM} \mathrm{KCl}, 101 \mathrm{mM} \mathrm{Na}_{2} \mathrm{HPO}_{4}, 18\right.$ $\mathrm{mM} \mathrm{KH}_{2} \mathrm{PO}_{4}$ ) with $0.5 \%$ v/v $\beta$-mercaptoethanol. Suspended cells were sonicated (Sonifier ${ }^{\circledR}$ ultrasonic cell disruptor) $8 \mathrm{~min}$ at voltage 6 with pulses of $0.6 \mathrm{~s}$, and then centrifuged for $40 \mathrm{~min}$ at $17,200 \times g(12,000 \mathrm{rpm})$ at $4{ }^{\circ} \mathrm{C}$.

Protein extracts containing GST-PbrMT1 or GST-PbrMT2 fusion proteins were incubated with glutathione sepharose beads (GE Healthcare) for $1 \mathrm{~h}$ at room temperature with gentle rotation. After centrifugation at $500 \times g(1553 \mathrm{rpm})$ for $5 \mathrm{~min}$, pellets of GST-PbrMT fusion proteins bound to the sepharose beads were washed by resuspending them in $30 \mathrm{~mL}$ of cold 1xPBS (20 mL for $3 \mathrm{~L}$ cultures) bubbled with argon to prevent oxidation. After three washes, GST-MT fusion proteins were digested with thrombin (GE Healthcare, $25 \mathrm{U} / \mathrm{L}$ of culture) overnight at $17^{\circ} \mathrm{C}$, enabling separation of the metal-PbrMT complexes from the GST that remained bound to the sepharose matrix. The eluted metal-PbrMT complexes 
were concentrated with a $3 \mathrm{kDa}$ Centripep Low Concentrator (Amicon, Millipore, MA, USA), and fractionated on a Superdex-75 FPLC column (GE Healthcare) equilibrated with $20 \mathrm{mM}$ Tris- $\mathrm{HCl}, \mathrm{pH}$ 7.0. Protein-containing fractions were identified by their absorbance at $254 \mathrm{~nm}$, and pooled and stored at $-80^{\circ} \mathrm{C}$ until use.

\subsection{Characterization of the Metal-PbrMT1 and Metal-PbrMT2 Complexes}

The different metal-MT recombinant preparations were characterized by means of Inductively Coupled Plasma Atomic Emission Spectrometer (ICP-AES), performed in an Optima 4300DV (Perkin-Elmer, Waltham, MA, USA) spectrometer by measuring $S$ at $182.04 \mathrm{~nm}, \mathrm{Zn}$ at $213.85 \mathrm{~nm}, \mathrm{Cd}$ at $228.80 \mathrm{~nm}$, and $\mathrm{Cu}$ at $324.75 \mathrm{~nm}$. The protein concentration was determined assuming that the total content of $S$ in the proteins comes from both cysteine and methionine amino acids [40]. However, some recombinant productions may render species that include labile $S^{-2}$ anions as a third component on the metal-MT complexes [41]. Therefore, two methodologies were performed to detect these labile sulfide anions. The so-called "conventional ICP" [40] that refers to the standard methodology used to measure the samples employing $1 \% \mathrm{HNO}_{3}$ solution as a matrix and the "acid ICP" [41] methodology that stands for those samples measured after incubation in $1 \mathrm{M} \mathrm{HNO}_{3}$ at $65{ }^{\circ} \mathrm{C}$ for $10 \mathrm{~min}$ to eliminate labile sulfide anions as $\mathrm{H}_{2} \mathrm{~S}$. Thus, the differences in $\mathrm{S}$ content measured via "conventional" and "acid" treatment allowed to detect the presence of labile sulfide anions in the samples. Moreover, the global metal to protein ratios were measured.

The molecular weight of Zn-, Cd- and Cu-MT complexes formed, as well as that of the corresponding apo proteins was determined by Electrospray Ionization Time-ofFlight Mass Spectrometry (ESI-TOF MS) on a Micro TOF-Q instrument (Bruker Daltonics, Bremen, Germany) connected to a Series 1200 HPLC Agilent pump and controlled by the Compass Software. Samples were analyzed under neutral ( $\mathrm{pH} 7.0$ ) and/or acidic ( $\mathrm{pH}$ 2.4) conditions, using as running buffer a 5:95 mixture of acetonitrile:ammonium acetate $(15 \mathrm{mM})$ and a 5:95 mixture of acetonitrile:formic acid solution, respectively. In acidic conditions, $\mathrm{Zn}(\mathrm{II})$ and $\mathrm{Cd}(\mathrm{II})$ are released while $\mathrm{Cu}(\mathrm{I})$ is kept in the protein complex. Therefore, the characterization of the apo proteins was performed at acidic conditions on the $\mathrm{Zn}$ - or Cd-loaded forms. For each analysis, $20 \mu \mathrm{L}$ of protein solution (of concentrations ranging between 20 and $129 \mu \mathrm{M}$ ) were injected at $30-40 \mu \mathrm{L} \cdot \mathrm{min}^{-1}$ and analyzed under the following conditions: capillary counter-electrode voltage, 3500-5000 V; dry temperature, 90-110 ${ }^{\circ} \mathrm{C}$; dry gas, $6 \mathrm{~L} \cdot \mathrm{min}^{-1} ; \mathrm{m} / \mathrm{z}$ range $800-3000$. Experimental masses were calculated as previously described [42].

Circular Dichroism (CD) measurements were performed in a Jasco spectropolarimeter (Model J-715; Jasco Inc., Easton, MD, USA) interfaced to a computer (J700 software). Electronic absorption was carried out by means of an HP-8453 Diode array UV-Visible spectrophotometer (Hewlett-Packard, Palo Alto, CA, USA). The resultant spectra from both techniques were processed with GRAMS 32 Software (GRAMS/AI v.7.02; Thermo Scientific, Walthman, MA, USA).

\subsection{In Vitro Metal-Protein Binding Studies}

Solutions of the Zn-PbrMT1 $(6.06 \mu \mathrm{M})$ and Zn-PbrMT2 $(6.84 \mu \mathrm{M})$ preparations were titrated with $\mathrm{Cd}(\mathrm{II})$ at $\mathrm{pH} 7.0$ as previously described $[27,43]$, using a $\mathrm{CdCl}_{2}$ standard solution of $1 \mathrm{mM}$ concentration. Essentially, a molar equivalent of metal was added by a stepwise manner to the protein solution. UV-Vis and CD spectra were recorded after each equivalent addition and once the spectrum, and hence the protein folding was stabilized. The procedure continued till metal saturation was reached. All the experiments were performed under strict oxygen-free conditions using argon to saturate the solutions. Aliquots of relevant equivalent additions were taken to execute MS analysis to draw, step by step, the evolution of each MT species throughout the displacement reaction.

Supplementary Materials: Supplementary materials are available online at https://www.mdpi. com/1422-0067/22/1/95/s1. 
Author Contributions: Conceptualization, R.D., M.C. and Ò.P.; methodology, R.A., M.C., Ò.P. and R.D.; software, S.C. and M.G.-R.; validation, R.D., M.C., Ò.P. and R.A.; formal analysis, S.C., M.N. and M.G.-R.; investigation, S.C., M.G.-R. and M.N.; resources, R.D., M.C. and R.A.; data curation, S.C., M.G.-R. and M.N.; writing-original draft preparation, M.C.; writing-review and editing, M.C., Ò.P., R.D., S.C., M.N. and M.G.-R.; visualization, S.C., M.G.-R., M.C. and R.D.; supervision, R.D., M.C., Ò.P. and R.A.; project administration, R.D., M.C. and R.A.; funding acquisition, R.D., M.C., Ò.P. and R.A. All authors have read and agreed to the published version of the manuscript.

Funding: Parts of this study were co-financed by a cooperation grant to R.D. from the Austrian Science Fund (DACH grant No I 1482-N28). Researchers from Barcelona want to acknowledge the Spanish Ministerio de Ciencia e Innovación and FEDER for the projects BIO2015-67358-C2-2-P (M.C. and Ò.P.) and BIO2015-67358-C2-1-P (R.A.). M.C. and Ò.P. are members of the "Grup de Recerca de la Generalitat de Catalunya", ref. 2017SGR-864, and R.A. of ref. 2017SGR-1665. M.G.-R. acknowledges to the UAB the PIF grant. We also thank the Servei d'Anàlisi Química (SAQ) at the Universitat Autònoma de Barcelona (ICP-AES, ESI-MS) for allocating instrument time, and the Centres Científics i Tecnològics (CCiT) at the Universitat de Barcelona for DNA sequencing.

Institutional Review Board Statement: Not applicable, no living animals involved.

Informed Consent Statement: Not applicable, no humans involved.

Data Availability Statement: Additional data for this work can be found in the Supplementary material. For access to raw data, please contact the corresponding author.

Acknowledgments: Open Access Funding by the Austrian Science Fund (FWF).

Conflicts of Interest: The authors declare no conflict of interests.

\section{References}

1. Kagi, J.H.R.; Vasák, M.; Lerch, K.; Gilg, D.; Hunziker, P.; Bernhard, W.; Good, M. Structure of mammalian metallothionein. Environ. Health Perspect. 1984, 54, 93-103. [PubMed]

2. Kägi, J.H.R.; Vallee, B.L. Metallothionein: A cadmium and zinc-containing protein from equine renal cortex. J. Biol. Chem. 1960, 235, 3460-3465. [PubMed]

3. Capdevila, M.; Bofill, R.; Palacios, O.; Atrian, S. State-of-the-art of metallothioneins at the beginning of the 21st century. Coord. Chem. Rev. 2012, 256, 46-62.

4. Vašák, M.; Bogumil, R.; Faller, P.; Hasler, D.W.; Binz, P.-A.; Klauser, S.; Bruinink, A.; Charnock, J.M.; Garner, C.D. Structural and biological studies on native bovine Cu,Zn-metallothionein-3. In Metallothionein IV: Advances in Life Sciences; Klaassen, C.D., Ed.; Birkhäuser: Basel, Switzerland, 1999; pp. 15-21.

5. Höckner, M.; Stefanon, K.; Vaufleury, A.; Monteiro, F.; Pérez-Rafael, S.; Palacios, O.; Capdevila, M.; Atrian, S.; Dallinger, R. Physiological relevance and contribution to metal balance of specific and non-specific Metallothionein isoforms in the garden snail Cantareus aspersus. Biometals 2011, 24, 1079-1092.

6. Dallinger, R.; Berger, B.; Hunziker, P.; Kägi, J.H.R. Metallothionein in snail Cd and Cu metabolism. Nature 1997, 388, 237-238. [PubMed]

7. Palacios, Ò.; Pagani, A.; Pérez-Rafael, S.; Egg, M.; Höckner, M.; Brandstätter, A.; Capdevila, M.; Atrian, S.; Dallinger, R. Shaping mechanisms of metal specificity in a family of metazoan metallothioneins: Evolutionary differentiation of mollusc metallothioneins. BMC Biol. 2011, 9, 4 .

8. Dvorak, M.; Lackner, R.; Niederwanger, M.; Rotondo, C.; Schnegg, R.; Ladurner, P.; Pedrini-Martha, V.; Salvenmoser, W.; Kremser, L.; Lindner, H.; et al. Metal binding functions of metallothioneins in the slug Arion vulgaris differ from metal-specific isoforms of terrestrial snails. Metallomics 2018, 10, 1638-1654.

9. Chabicovsky, M.; Niederstätter, H.; Thaler, R.; Höld, E.; Parson, W.; Rossmanith, W.; Dallinger, R. Localization and quantification of $\mathrm{Cd}$ - and Cu-specific metallothionein isoform mRNA in cells and organs of the terrestrial gastropod Helix pomatia. Toxicol. Appl. Pharmacol. 2003, 190, 25-36.

10. Hödl, E.; Felder, E.; Chabicovsky, M.; Dallinger, R. Cadmium stress stimulates tissue turnover in Helix pomatia: Increasing cell proliferation from metal tolerance to exhaustion in molluscan midgut gland. Cell Tissue Res. 2010, 341, $159-171$.

11. Dallinger, R.; Chabicovsky, M.; Hödl, E.; Prem, C.; Hunziker, P.; Manzl, C. Copper in Helix pomatia (Gastropoda) is regulated by one single cell type: Differently responsive metal pools in rhogocytes. Am. J. Physiol. Regul. Comp. Physiol. 2005, 289, 1185-1195.

12. Pérez-Rafael, S.; Monteiro, F.; Dallinger, R.; Atrian, S.; Palacios, Ò.; Capdevila, M. Cantareus aspersus metallothionein metal binding abilities: The unspecific $\mathrm{CaCd} / \mathrm{CuMT}$ isoform provides hints about the metal preference determinants in metallothioneins. Biochim. Biophys. Acta 2014, 1844, 1694-1707. [PubMed]

13. Dallinger, R.; Zerbe, O.; Baumann, C.; Egger, B.; Capdevila, M.; Palacios, Ò.; Albalat, R.; Calatayud, S.; Ladurner, P.; SchlickSteiner, B.C.; et al. Metallomics reveals a persisting impact of cadmium on the evolution of metal-selective snail metallothioneins. Metallomics 2020, 12, 702-720. [PubMed] 
14. Palacios, Ò.; Pérez-Rafael, S.; Pagani, A.; Dallinger, R.; Atrian, S.; Capdevila, M. Cognate and noncognate metal ion coordination in metal-specific metallothioneins: The Helix pomatia system as a model. J. Biol. Inorg. Chem. 2014, 19, 923-935. [PubMed]

15. Hispard, F.; Schuler, D.; de Vaufleury, A.; Scheifler, R.; Badot, P.-M.; Dallinger, R. Metal distribution and metallothionein induction after cadmium exposure in the terrestrial snail Helix aspersa (Gastropoda, Pulmonata). Environ. Toxicol. Chem. 2008, 27, 1533-1542. [PubMed]

16. Coyle, P.; Philcox, J.; Carey, L.; Rofe, A. Metallothoinein: The multipurpose protein. Cell. Mol. Life Sci. 2002, 59, 627-647. [PubMed]

17. Feng, W.; Cai, J.; Pierce, W.; Franklin, R.; Maret, W.; Benz, F.; Kang, J. Metallothionein transfers zinc to mitochondrial aconitase through a direct interaction in mouse hearts. Biochem. Biophys. Res. Commun. 2005, 332, 853-858.

18. Loebus, J.; Leitenmaier, B.; Meissner, D.; Braha, B.; Krauss, G.-J.; Dobritzsch, D.; Freisinger, E. The major function of a metallothionein from the aquatic fungus Heliscus lugdunensis is cadmium detoxification. J. Inorg. Biochem. 2013, 127, $253-260$.

19. Bofill, R.; Capdevila, M.; Atrian, S. Independent metal-binding features of recombinant metallothioneins convergently draw a step gradation between $\mathrm{Zn}$ - and Cu-thioneins. Metallomics 2009, 1, 229-234.

20. Palacios, Ò.; Atrian, S.; Capdevila, M. Zn- and Cu-thioneins: A functional classification for metallothioneins? J. Biol. Inorg. Chem. 2011, 16, 991-1009.

21. Pérez-Rafael, S.; Mezger, A.; Lieb, B.; Dallinger, R.; Capdevila, M.; Palacios, O.; Atrian, S. The metal binding abilities of Megathura crenulata metallothionein (McMT) in the frame of Gastropoda MTs. J. Inorg. Biochem. 2012, 108, 84-90.

22. Niederwanger, M.; Calatayud, S.; Zerbe, O.; Atrian, S.; Albalat, R.; Capdevila, M.; Palacios, Ò.; Dallinger, R. Biomphalaria glabrata metallothionein: Lacking metal specificity of the protein and missing gene upregulation suggest metal sequestration by exchange instead of through selective binding. Int. J. Mol. Sci. 2017, 18, 1457. [CrossRef] [PubMed]

23. Calatayud, S.; Garcia-Risco, M.; Pedrini-Martha, V.; Eernisse, D.J.; Dallinger, R.; Palacios, Ò.; Capdevila, M.; Albalat, R. Modularity in protein evolution: Modular organization and de novo domain evolution in mollusc metallothioneins. Mol. Biol. Evol. 2020, msaa230. [CrossRef] [PubMed]

24. Yang, Q.-Q.; Yu, X.-P. A new species of apple snail in the genus Pomacea (Gastropoda: Caenogastropoda: Ampullariidae). Zool. Stud. 2019, 58, 1-7.

25. Halwart, M. The golden apple snail Pomacea canaliculata in Asian rice farming systems: Present impact and future threat. Int. J. Pest Manag. 1994, 40, 199-206. [CrossRef]

26. Horgan, F.B. The ecophysiology of apple snails in rice: Implications for crop management and policy. Ann. Appl. Biol. 2018, 172, 245-267. [CrossRef]

27. Capdevila, M.; Cols, N.; Romero-Isart, N.; González-Duarte, R.; Atrian, S.; González-Duarte, P. Recombinant synthesis of mouse Zn3- $\beta$ and Zn4- $\alpha$ metallothionein 1 domains and characterization of their cadmium(II) binding capacity. Cell. Mol. Life Sci. 1997, 53, 681-688. [CrossRef] [PubMed]

28. Cols, N.; Romero-Isart, N.; Capdevila, M.; Oliva, B.; González-Duarte, P.; González-Duarte, R.; Atrian, S. Binding of excess cadmium(II) to Cd7-metallothionein from recombinant mouse Zn7-metallothionein 1. UV-VIS absorption and circular dichroism studies and theoretical location approach by surface accessibility analysis. J. Inorg. Biochem. 1997, 68, 157-166. [CrossRef]

29. Baumann, C.; Beil, A.; Jurt, S.; Niederwanger, M.; Palacios, O.; Capdevila, M.; Atrian, S.; Dallinger, R.; Zerbe, O. Structural adaptation of a protein to increased metal stress: NMR structure of a marine snail metallothionein with an additional domain. Angew. Chem. Int. Ed. 2017, 56, 4617-4622. [CrossRef]

30. Palacios, Ò.; Jiménez-Martí, E.; Niederwanger, M.; Gil-Moreno, S.; Zerbe, O.; Atrian, S.; Dallinger, R.; Capdevila, M. Analysis of metal-binding features of the wild type and two domain-truncated mutant variants of Littorina littorea metallothionein reveals its Cd-specific character. Int. J. Mol. Sci. 2017, 18, 1452. [CrossRef]

31. Schmielau, L.; Dvorak, M.; Niederwanger, M.; Dobieszewski, N.; Pedrini-Martha, V.; Ladurner, P.; Rodríguez-Guerra Pedregal, J.; Maréchal, J.-D.; Dallinger, R. Differential response to cadmium exposure by expression of a two and a three-domain metallothionein isoform in the land winkle Pomatias elegans: Valuating the marine heritage of a land snail. Sci. Total Environ. 2019, 648, 561-571. [CrossRef]

32. Beil, A.; Jurt, S.; Walser, R.; Schönhut, T.; Güntert, P.; Palacios, Ò.; Atrian, S.; Capdevila, M.; Dallinger, R.; Zerbe, O. The solution structure and dynamics of Cd-metallothionein from Helix pomatia reveal optimization for binding Cd over Zn. Biochemistry 2019, 58, 4570-4581. [CrossRef]

33. Blindauer, C.A. Metallothioneins with unusual residues: Histidines as modulators of zinc affinity and reactivity. J. Inorg. Biochem. 2008, 102, 507-521. [CrossRef]

34. Blindauer, C.A.; Razi, M.T.; Campopiano, D.J.; Sadler, P.J. Histidine ligands in bacterial metallothioneins enhance cluster stability. J. Biol. Inorg. Chem. 2007, 12, 393-405. [CrossRef]

35. Perinelli, M.; Tegoni, M.; Freisinger, E. Different behavior of the histidine residue toward cadmium and zinc in a cadmium-specific metallothionein from an aquatic fungus. Inorg. Chem. 2020, 59, 16988-16997. [CrossRef] [PubMed]

36. Vergani, L.; Grattarola, M.; Grasselli, E.; Dondero, F.; Viarengo, A. Molecular characterization and function analysis of MT-10 and MT-20 metallothionein isoforms from Mytilus galloprovincialis. Arch. Biochem. Biophys. 2007, 465, 247-253. [CrossRef]

37. Orihuela, R.; Domènech, J.; Bofill, R.; You, C.; Mackay, E.; Kägi, J.H.R.; Capdevila, M.; Atrian, S. The metal-binding features of the recombinant mussel Mytilus edulis MT-10-IV metallothionein. J. Biol. Inorg. Chem. 2008, 13, 801-812. [CrossRef] [PubMed] 
38. Maltez, H.F.; Villanueva Tagle, M.; Fernández de la Campa, M.d.R.; Sanz-Mendel, A. Metal-metallothioneins like proteins investigation by heteroatom-tagged proteomics in two different snails as possible sentinel organisms of metal contamination in freshwater ecosystems. Anal. Chim. Acta 2009, 655, 234-240. [CrossRef] [PubMed]

39. Calatayud, S.; Garcia-Risco, M.; Rojas, N.; Espinosa-Sánchez, L.; Artime, S.; Palacios, Ò.; Cañestro, C.; Albalat, R. Metallothioneins of the urochordate Oikopleura dioica have Cys-rich tandem repeats, large size and cadmium-binding preference. Metallomics 2018, 10, 1585-1594. [CrossRef]

40. Bongers, J.; Walton, C.D.; Richardson, D.E. Micromolar protein concentrations and metalloprotein stoichiometries obtained by inductively coupled plasma atomic emission spectrometric determination of sulfur. Anal. Chem. 1988, 60, 2683-2686. [CrossRef]

41. Capdevila, M.; Domènech, J.; Pagani, A.; Tío, L.; Villarreal, L.; Atrian, S. Zn- and Cd-metallothionein recombinant species from the most diverse phyla may contain sulfide (S2-) ligands. Angew. Chem. Int. Ed. 2005, 44, 4618-4622. [CrossRef]

42. Fabris, D.; Zaia, J.; Hathout, Y.; Fenselau, C. Retention of thiol protons in two classes of protein zinc ion coordination centers. J. Am. Chem. Soc. 1996, 118, 12242-12243. [CrossRef]

43. Bofill, R.; Palacios, Ò.; Capdevila, M.; Cols, N.; González-Duarte, R.; Atrian, S.; González-Duarte, P. A new insight into the Ag+ and $\mathrm{Cu}+$ binding sites in the metallothionein beta domain. J. Inorg. Biochem. 1999, 73, 57-64. [CrossRef] 